\title{
EFFECT OF QUENCHING AND TEMPERING ON MICRO STRUCTURE AND MECHANICAL PROPERTIES IN LATERITE STEEL
}

\author{
Desiran Sembiring ${ }^{1}$, Djoko Setyo Widodo ${ }^{2}$ and Bintang Adjiantoro ${ }^{3}$ \\ ${ }^{1}$ PhD Candidate Faculty of Mechanical Engineering Program of Technology \\ University of Malaysia \\ ${ }^{2}$ PhD Candidate Faculty of Mechanical Engineering Program Technology \\ University of Malaysia and Lecture at Universitas Krinadwipayana Jakarta, \\ Indonesia \\ ${ }^{3}$ Metallurgical Research Center LIPI, Serpong PUSPIPTEK Complex \\ ${ }^{1}$ desmuham@gmail.com, ${ }^{2}$ djokosetyowidodo@gmail.com, \\ 3bintangadjiantoro@yahoo.co.id
}

\begin{abstract}
The need for high armor material has an impact on the use of laterite steel as an armor material. Therefore the increase of the mechanical properties in laterite steel needs to be done. One way to improve mechanical properties in steel is through quenching and tempering. The variables used in this study are variations in cooling media (water, oil, and air) and tempering temperatures $\left(0^{\circ} \mathrm{C}, 100^{\circ} \mathrm{C}\right.$, and $200^{\circ} \mathrm{C}$ ). This study used the experimental method using metallographic observations under optical microscopy, hardness value using Rockwell hardness method, tensile strength values using tensile testing machines and standard ASTM E8, as well as impact resistance values using the Charpy type impact testing machine and ASTM E23 standard.

The results showed that specimens from quenching with medium water at a tempering temperature of $100^{\circ} \mathrm{C}$ had the highest average hardness and tensile strength. This is due to the relatively high content of martensite. The highest impact resistance is owned by specimens from quenching oil followed by tempering at $100^{\circ} \mathrm{C}$. In some specimens, there was a secondary hardening event or an increase in hardness after the tempering process and tempered martensite embrittlement event namely the impact resistance value which actually decreased after going through the tempering process.
\end{abstract}

Keywords - quenching, tempering, microstructure, mechanical properties, laterite steel

\section{INTRODUCTION}

The need for bullet-proof material that is light in bullet-proof vehicles is very necessary in order to improve the ability of vehicle mobility and also the efficiency of fuel consumption. Steel has long been used as an armor material. Steel was chosen because of its good mechanical properties and easy characterization. In addition, the availability of steel which is quite large and easy for machinery to process a steel material that is often chosen as bulletproof material (Beny, 2010).

Received: July 1, 2019

Reviewed: October 15, 2019

Accepted: November 11, 2019 
The national metal industry is expected to be able to produce steel armor as a component in the manufacture of combat vehicles. Improving Quality in terms of mechanical properties needs to be carry out an analysis and further study to obtain the performance of domestically-made armor steel which is able to compete with steel armor made in other countries, so that domestic armor steel can be used as a substitute for armor steel which must be imported from other countries (Yanuar et al, 2014).

Indonesia has considerable iron ore resource potential, in the form of primary iron ore with estimated reserves of up to 320 billion kilograms with $52 \%$ to $66 \% \mathrm{Fe}$ content, laterite iron ore with estimated reserves of up to 1,391 billion kilograms with $\mathrm{Fe}$ content of $40 \%$ to $56 \%$, and iron sand with estimated reserves of up to 600 billion kilograms with Fe content of $25 \%$ to $40 \%$ (Koesnohadi and Sobandi, 2008). The biggest potential resource in Indonesia is the type of laterite ore which is known to be spread in South Kalimantan, Sulawesi, and Halmahera (Sufriadin et al, 2013). Laterite ores are iron ore containing $\mathrm{Ni}$ and $\mathrm{Cr}$ (Yusuf and Herianto, 2008).

To get a material that is resistant to ballistics, an optimal combination of hardness, tenacity and toughness is needed. Hardened steel has been widely applied as bullet resistant material. The strength and toughness properties that can be improved through mechanical processes and heat treatment are the main reasons for using steel as a construction material including bullet-resistant construction (Purwanto et al, 2015). Ballistic resistant material (armor) is a material used to provide fire protection (National Institute of Justice U.S. Department of Justice, 1985). To produce a product that requires tenacity and resistance to friction, it is necessary to do a reheating or tempering process. The purpose of tempering is to increase tenacity and reduce friability by reducing the level of hardness (Haryadi, 2006). The type of heat treatment for medium carbon steel is annealing to soften steel in cold work or in the machining process, customizing to form austenite structure and decompose all or part of its carbide, cooling or quenching to convert austenite to martensite which is then followed by tempering on the martensitic structure to improve durability and tenacity (Barlow and Toit, 2012).

In an effort to develop national armor steel production and the use of laterite iron ore resources as the biggest potential in Indonesia, it is important for the study of the effect of quenching and tempering on microstructure and the improvement of mechanical properties in laterite steel including hardness, tensile strength and impact resistance.

\section{THEORY BACKGROUND}

\subsection{LATERITE STEEL}

Laterite steel is steel that has much better mechanical properties than carbon steel and stainless steel because it has a $\mathrm{Ni}$ content of $0 \%$ to $3.0 \%$ and $\mathrm{Cr}$ of $0 \%$ to $2.5 \%$ (Zeng, 2016). In addition to the content of $\mathrm{Fe}$ and $\mathrm{Ni}$, laterite steel also contains other elements namely $\mathrm{Cr}$ and $\mathrm{Mn}$ where both of these elements will have an impact on weldability steel properties, surface hardness, and corrosion resistance (Herbirowo and Adjiantoro, 2016). Laterite steel is widely used as the main material in piping systems, hydroelectric power plants, petrochemicals and the nuclear power industry because of its long service life, corrosion resistance, easy to be given coating treatment, and economical (Zeng, 2016).

\subsection{QUENCHING}

Quenching is a sudden process of cooling metal from austenite treatment, usually at a metal temperature between $815-870^{\circ} \mathrm{C}\left(1,500-1,600^{\circ} \mathrm{F}\right)$ to form a phase of martensite and bainite microstructure. The cooling media that is most often used is liquid and gas. Cooling media with liquid phase commonly used, namely oil, water, aqueous polymer solution, and water containing salt or lime. While the most commonly used gas-based cooling media are helium, argon, and nitrogen. The choice of pending media depends on 
the ability of the alloy to be hardened, the thickness of the material, the shape of the material, and the rate of cooling needed to obtain the desired microstructure. The basic function of the cooling media is to adjust the rate of heat transfer from the surface of the quenched material. The effectiveness of the quenching process depends on the composition of the metal, the type of cooling media, or the conditions at the time of quenching. The quenching system and implementation of the quenching system also contribute to the success of quenching (ASM International, 1991).

\subsection{TEMPERING}

The tempering process is the heating process of metals or alloys in a solid state to obtain certain properties (Ahmad, 2012). The purpose of doing the reheating or tempering process is to produce products that have tenacity, reduce friability, and are resistant to friction. The effect of temperature on the tempering process will reduce the hardness of the metal (Haryadi, 2006). Tempering temperature, the time required at that temperature, the cooling rate of tempering temperature, and a composition contained in steel including carbon content, alloys, and residual elements are some of the variables that affect the microstructure and mechanical properties of steel which has undergone a tempering process (ASM International, 1991).

\subsection{MICRO-STRUCTURE}

Differences in macrostructure and microstructure exist in its size, the macrostructure is a structure that can be seen by the naked eye of humans with a size above $100 \mu \mathrm{m}$ whereas, microstructures are classified as structures with sizes from $100 \mu \mathrm{m}$ to $1 \AA$. The mechanical properties and physical properties of a material depend on the microstructure of the material (ASM International, 2004). The microstructure is one of the subjects in direct microscopic observation using optical microscopy and electron microscopy. In alloy steel, the microstructure is characterized by the number of phases present, their proportions, and how they are distributed or arranged rather than that phase. The microstructure of the alloy depends on many variables such as alloy elements added, concentration, and heat treatment carried out on the alloy, including heat treatment temperature, heating time, and cooling rate used at room temperature (Junior and Rethwisch, 2016). The majority of the constituent elements of the material have microscopic dimensions with micron-sized diameters and for more details can only be observed using a variety of microscopes. The size and shape of the grains are two things that can be observed in the microstructure. Optical microscopes, electrons, and scanning probes are the microscopes most often used to observe microstructure in all types of material.

\subsection{MECHANICAL PROPERTIES}

The mechanical properties of a material are the ability of the material to withstand the loads imposed on it. These loads can be compressive, tensile, sliding, bent, twisted, or combined loads (Arief. 2012). Mechanical properties include hardness, tensile strength, impact resistance, and stretch strength (Mishra et al, 2009).

Hardness can be defined as the ability of a material to withstand scratches, abrasion and penetration. This property is closely related to wear properties. Where this violence also has a correlation with strength (Arief. 2012). Hardness testers emphasize indentors or presses in the form of small balls, pyramids, or cones to metal surfaces with certain loads and hardness numbers obtained from trace diameter (Ahmad, 2012). Hardness can be related to yield stress or tensile stress because, during indentation, the material around the indentor trail undergoes plastic deformation which reaches several percent strain (Smallman and Bishop, 1995). There are three types of hardness that depend on how they are carried out, namely Rockwell, Brinell, and Vikers hardness tests (Haryadi, 2006). 
Tensile strength is widely used as a way to find out the strength of a material. The stress-strain curve is obtained from extension-load measurements, some points on the stress-strain curve are important considerations (George, 1986). Tensile stress is when the voltage reaches the maximum level in the stress-strain technique curve. Tensile stress indicates the maximum stress that can be supported by a structure. Tensile stress varies from $50 \mathrm{MPa}(7,000 \mathrm{Psi})$ in aluminum to $3,000 \mathrm{MPa}(450,000 \mathrm{Psi})$ in high strength steel (15). The shape and size of the stress-strain curve in metals are based on composition, heat treatment, initial plastic deformation, strain rate, temperature, and the voltage applied during the test. The parameters that can be obtained from the stress-strain curve are tensile stress, yield stress, elongation percentage, and area reduction as shown in Figure 2.24. Tensile stress and yield stress are parameters of material strength. The percentage of elongation and area reduction is a material tenacity parameter (George, 1986).

Materials may have high tensile stress but are not resistant to shock loads or impact. To determine impact resistance, an impact resistance test is required. Impact resistance is usually measured by the Izod or Charpy impact test for the test object notched or without a notch. In this test the load is swung from a certain height so that it is subject to the test object, then the dissipation energy on the fault is measured. This test is useful for showing a decrease in ductility and material impact resistance Kingdom (Smallman and Bishop, 1995). The Charpy impact test specimen is the most commonly used in the United States whereas, for the Izod impact test specimen it is the most preferred for use in the United Kingdom (Smallman and Bishop, 1995).

\section{RESEARCH METHOD}

This study used the experimental method, namely the research method used to find the effect of certain treatments on others in controlled conditions (Sugiyono, 2012). The treatment referred to in this study is in the form of a quenching and tempering process on laterite steel. The results obtained in the form of changes that occur in microstructure using metallographic observations under optical microscopy, hardness value using Rockwell hardness method, tensile strength values using tensile testing machines and standard ASTM E8, as well as impact resistance values using the Charpy type impact testing machine and ASTM E23 standard.

\section{RESEARCH RESULTS AND DISCUSSION}

The result of this research is microstructure, hardness value, tensile strength value, yield strength value, elongation, and energy which can be absorbed in laterite steel which has been heat treatment with variation in coolant media and tempering temperature $\mathrm{R}$ (raw material or without treatment), QA (quenching water only, without tempering), A1 (quenching water and tempering at $100^{\circ} \mathrm{C}$ ), A2 (quenching water and tempering at $200^{\circ} \mathrm{C}$ ), $\mathrm{QO}$ (only oil quenching process, without tempering), $\mathrm{O} 1$ (oil quenching and tempering at $100^{\circ} \mathrm{C}$ ), $\mathrm{O} 2$ (oil quenching and tempering at $200^{\circ} \mathrm{C}$ ), QU (only processed quenching air without tempering), U1 (quenching air and tempering at $100^{\circ} \mathrm{C}$ ), and $\mathrm{U} 2$ (quenching air and tempering at $\left.200^{\circ} \mathrm{C}\right)$.

\subsection{COMPOSITION TEST RESULTS}

Table I. Chemical Composition Test Results

\begin{tabular}{|c|c|}
\hline Matter & Chemical Composition (\%) \\
\hline $\mathrm{Ti}$ & 0,00191 \\
\hline $\mathrm{Zr}$ & 0,00247 \\
\hline $\mathrm{Pb}$ & 0,00295 \\
\hline $\mathrm{Sn}$ & 0,00324 \\
\hline $\mathrm{V}$ & 0,00385 \\
\hline
\end{tabular}




\begin{tabular}{|c|c|}
\hline Matter & Chemical Composition (\%) \\
\hline $\mathrm{Zn}$ & 0,00519 \\
\hline $\mathrm{S}$ & 0,03350 \\
\hline $\mathrm{Co}$ & 0,03969 \\
\hline $\mathrm{P}$ & 0,04400 \\
\hline $\mathrm{Mn}$ & 0,08510 \\
\hline $\mathrm{Al}$ & 0,18422 \\
\hline $\mathrm{Si}$ & 0,20938 \\
\hline $\mathrm{C}$ & 0,27013 \\
\hline $\mathrm{Mo}$ & 0,42926 \\
\hline $\mathrm{Cr}$ & 0,55362 \\
\hline $\mathrm{Ni}$ & 1,78331 \\
\hline $\mathrm{Fe}$ & 96,3470 \\
\hline
\end{tabular}

Viewed from the table of the results of the chemical composition of laterite steel above, the laterite steel can be classified into medium carbon steel by looking at the requirement that steel can be classified into medium carbon steel if the carbon element is between $0.20 \%$ to $0.50 \%$ (Surdia and Chijiwa, 2000).

In the heat treatment process there is the formation of the maximum martensite phase in medium carbon steel (Mishra et al, 2009), the microstructure formed from the tempering process of medium carbon steel is martensite, where the martensitic structure will affect the increase in steel hardness value (Jena et al, 2008), and the purpose of the heat process treatment is to increase hardness, tenacity, tensile strength and impact resistance on steel (Arief, 2012).

\subsection{METALLOGRAPHIC TEST RESULTS}

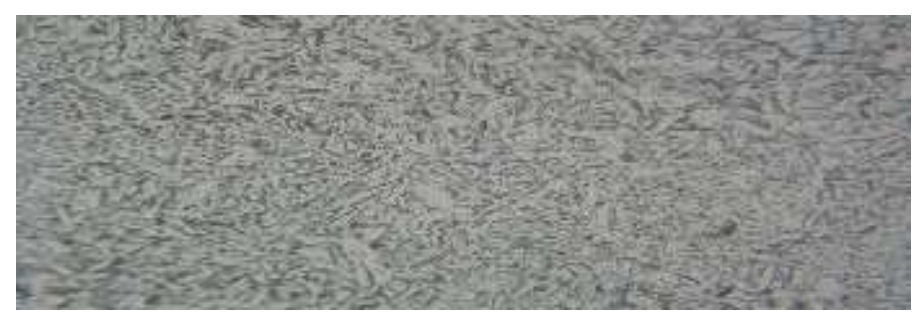

Fig. 1 The Metallographic test results of a raw material specimen

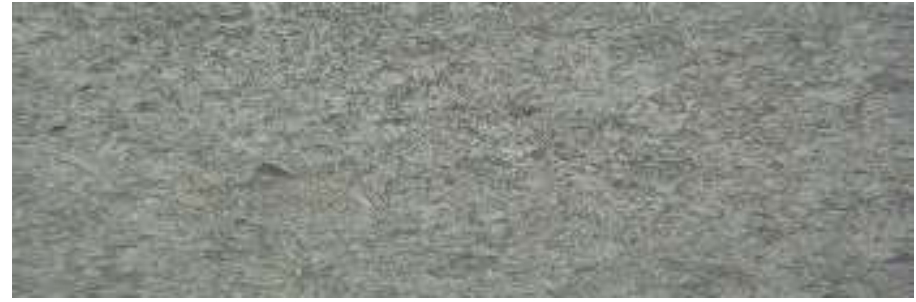

Fig. 2 Metallographic test results of quenching water tempering temperature $\mathbf{0}^{\circ} \mathbf{C}$

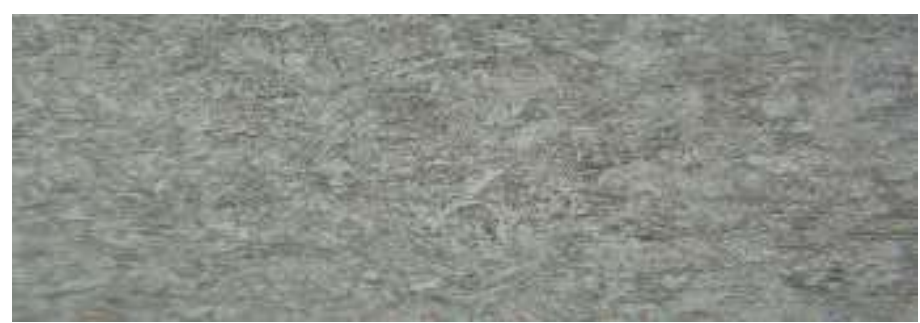

Fig. 3 Metallographic test results of quenching water tempering temperature $100^{\circ} \mathrm{C}$ 


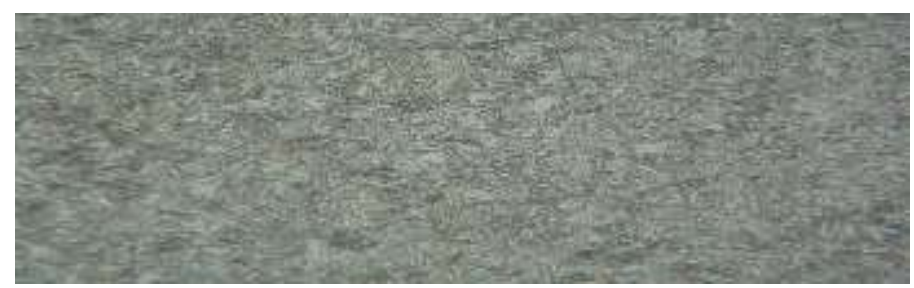

Fig. 4 Metallographic test results of quenching water tempering temperature $200^{\circ} \mathrm{C}$

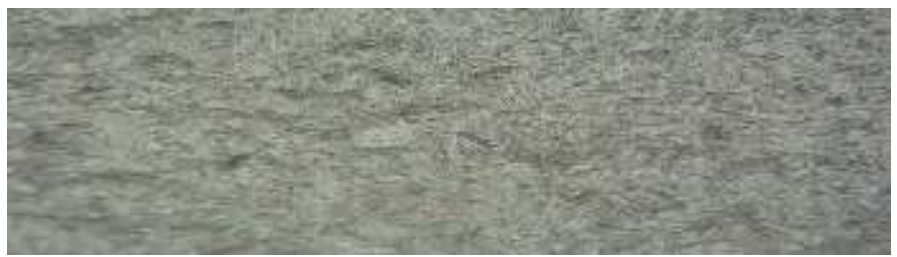

Fig. 5 Metallographic test results of specimens quenching oil tempering temperature $0^{\circ} \mathrm{C}$

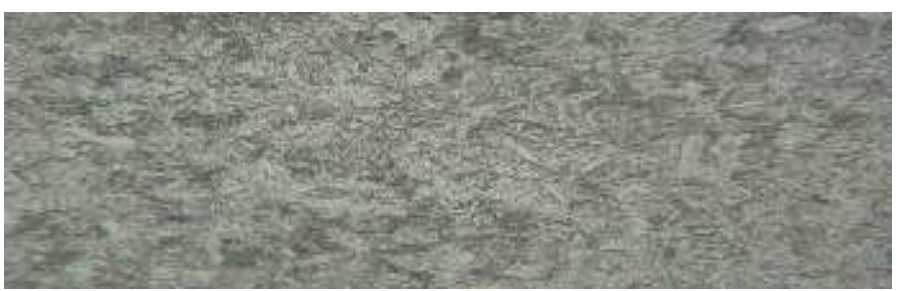

Fig. 6 Metallographic test results of specimens quenching oil tempering temperature $100^{\circ} \mathrm{C}$

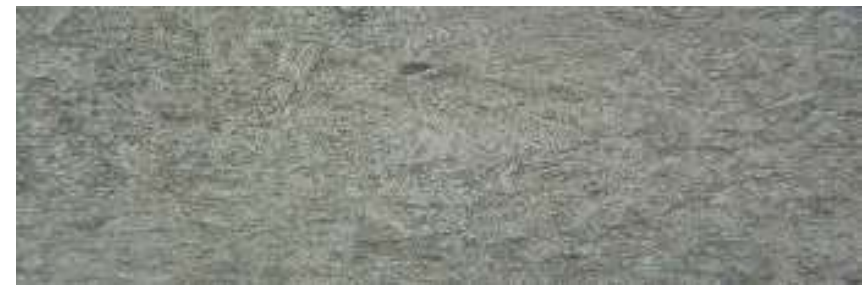

Fig. 7 Metallographic test results of specimens quenching oil tempering temperature $200^{\circ} \mathrm{C}$

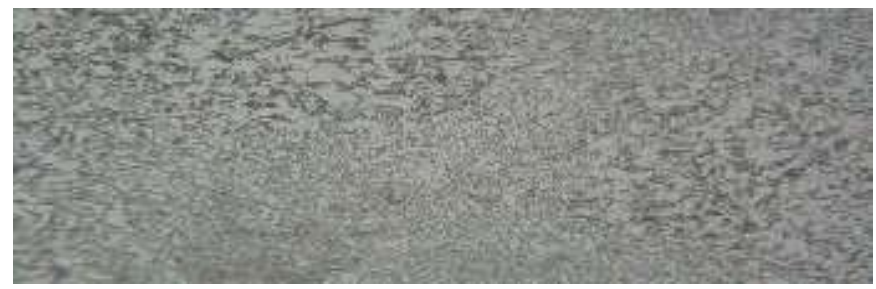

Fig. 8 Metallographic test results of specimens quenching air tempering temperature $0^{\circ} \mathrm{C}$

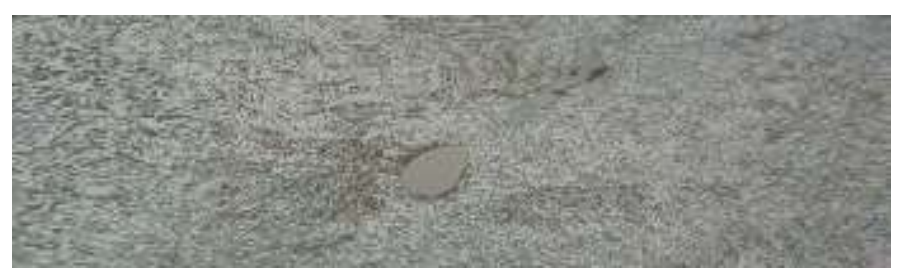

Fig. 9 Metallographic test results of specimens quenching air tempering temperature $100^{\circ} \mathrm{C}$ 


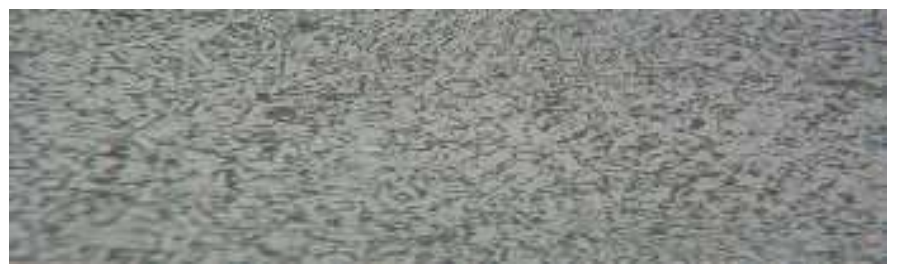

Fig. 10 Metallographic test results of specimens quenching air tempering temperature $200^{\circ} \mathrm{C}$

From the overall data that have been presented in the form of drawings, in general, the process of treatment which in this study includes quenching and tempering can affect the phase transformation of material microstructure.

The results showed that the microstructure formed from the tempering process was residual martensite and austenite (Jena et al, 2008). The martensite phase will affect the increase in the hardness value and the tensile strength of the material, however, the internal stress that occurs during the formation of the martensite phase can reduce the value of ductility and material durability. The purpose of the tempering process is to increase the impact resistance value, however, in the low-temperature tempering process, it can cause tempering martensite brilliance or commonly refer to as tempered martensite embrittlement, which will result in decreased material impact resistance. Residual austenite is found in specimens A1, A2, QO, and U2 where the residual austenite affects secondary hardening events that appear on the hardness of specimens A1, A2, and U2. The remaining austenite in the A1 and A2 specimens also affected the linear stress and tensile stresses of the two specimens. In addition, the impact test results on QO specimens which were lower than raw materials were also caused by the presence of residual austenite.

In some specimens also found the micro- $\varepsilon$-carbide structure. $\varepsilon$-carbide is found in specimens QA, A1, O1, O2, and at $\mathrm{U} 2$, where the $\varepsilon$-carbide also has a role in the presence of secondary hardening processes, increases in tensile strength, decreased elongation, and the occurrence of tempered martensite embrittlement in these specimens. The microstructure of ferrite and pearlite as in raw material is owned by QU, U1, and U2 specimens because the specimens are quenched with air cooling media where the air cooling rate is very low, as ASM International (1991: 172) states low will cause changes in the microstructure of austenite to ferrite and pearlite.

\subsection{HARDNESS TEST RESULTS}

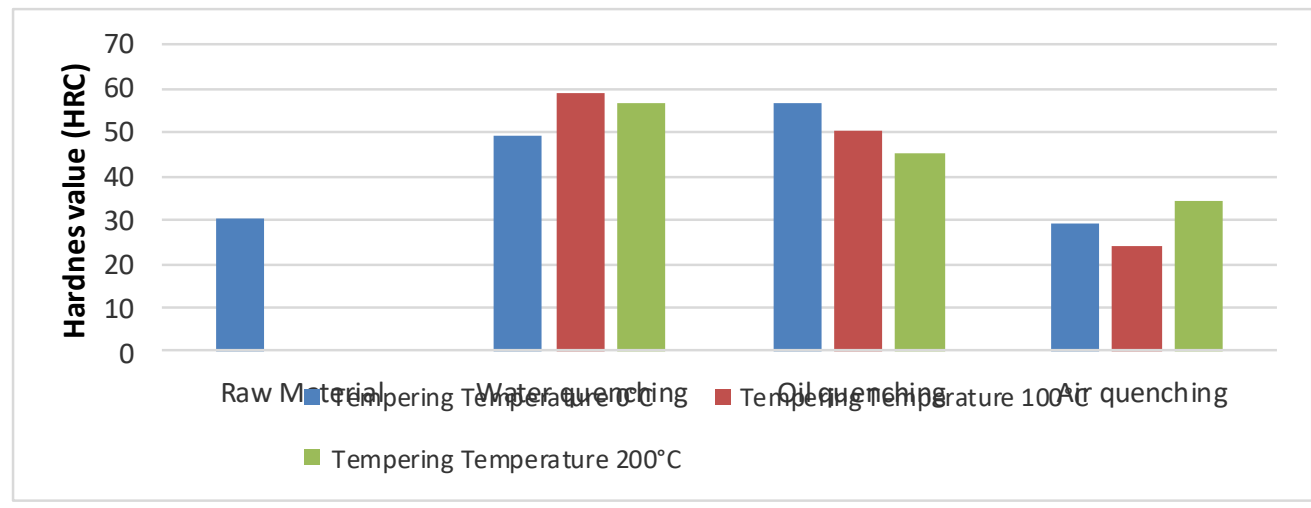

Fig. 11 Effect of Cooling Media on Hardness at Each Tempering Temperature

From the overall data presented, the material undergoing the quenching process has a higher hardness value compared to the material without quenching. This is due to the 
presence of the martensitic phase in the microstructure where the martensite phase is the metastable hard phase.

Data also show that variations in cooling media will produce variations in the value of hardness, the type of cooling media determines the amount of cooling rate and the higher the heat propagation coefficient, the higher the cooling rate which affects the value of hardness produced (ASM International, 1991). Quenching water has the highest hardness, followed by the hardness value of the oil quenching process and the last is the hardness value from the air quenching process. This is because the water cooling rate is the highest among the three which is marked by the Grossman number (cooling rate number) which is owned by water as much as 1.1 while the Grossman oil number is 0.7 , and the air is 0.05 . The type of cooling media used in the quenching process affects the hardness value of a material. In general, the increase in tempering temperature can reduce the value of material hardness, that the increase in tempering temperature is inversely proportional to the value of material hardness (Jena et al, 2000);(Liu et al, 2016), but different things are shown in specimen data from quenching water followed by tempering at $100^{\circ} \mathrm{C}$ and quenching air specimens tempering temperature of $200^{\circ} \mathrm{C}$ where the value of hardness increases. There are several types of steel which when processed tempering is not affected by the value of hardness, in steel containing one or more carbide forming elements $(\mathrm{Cr}, \mathrm{Mo}, \mathrm{V}$, and $\mathrm{W})$, the steel can experience secondary hardening which is a condition where after experiencing tempering the material hardness will increase. Carbide forming elements such as $\mathrm{Cr}$, Mo, and $\mathrm{V}$ are the most effective elements in increasing material hardness. Secondary hardening occurs due to the relatively large transformation of the remaining austenite phase. Most steel with heat treatment has secondary hardening characteristics. To avoid the occurrence of secondary hardening, it is recommended to temporize at a higher temperature to obtain the desired hardness.

\subsection{TENSILE TEST RESULTS}

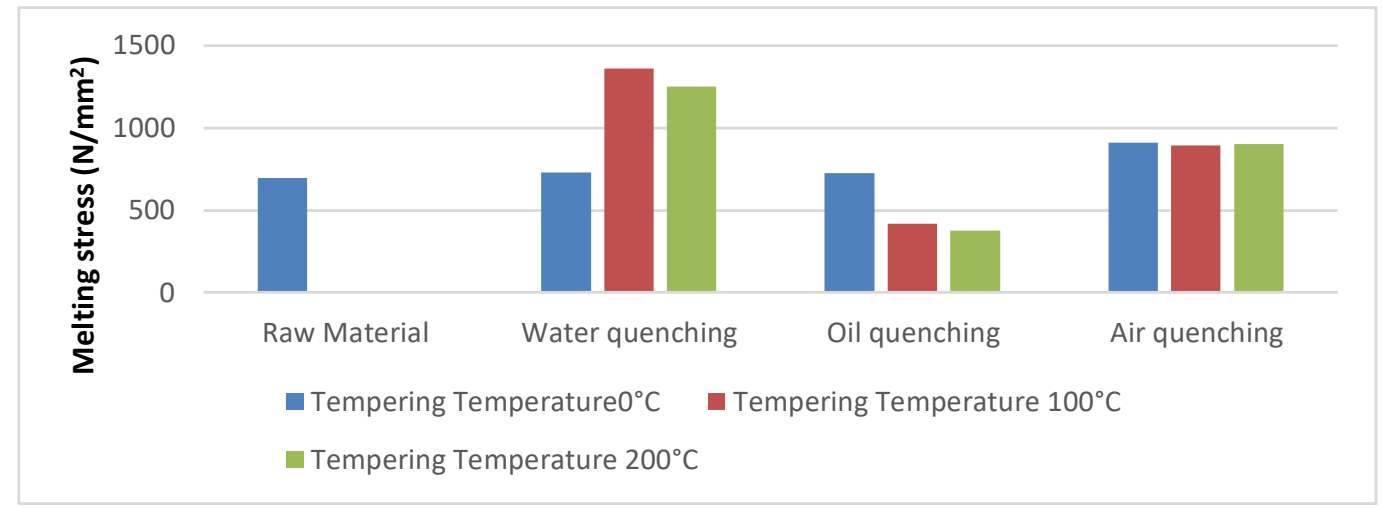

Fig. 12 Effect of Cooling Media on Yield Voltage at Each Tempering Temperature

In the tensile test data, it can be seen that after experiencing the quenching process, the tensile stress will increase, the tensile strength will increase due to a phase change which is initially in the form of austenite and then changes to harder martensite (Jena et al, 2009). This is as a result of the process of forming martensite coupled with a large amount of distortion that will rapidly increase the strength and hardness of the material, but the internal stresses that appear in the martensite formation process can cause a significant decrease in ductility and durability. 


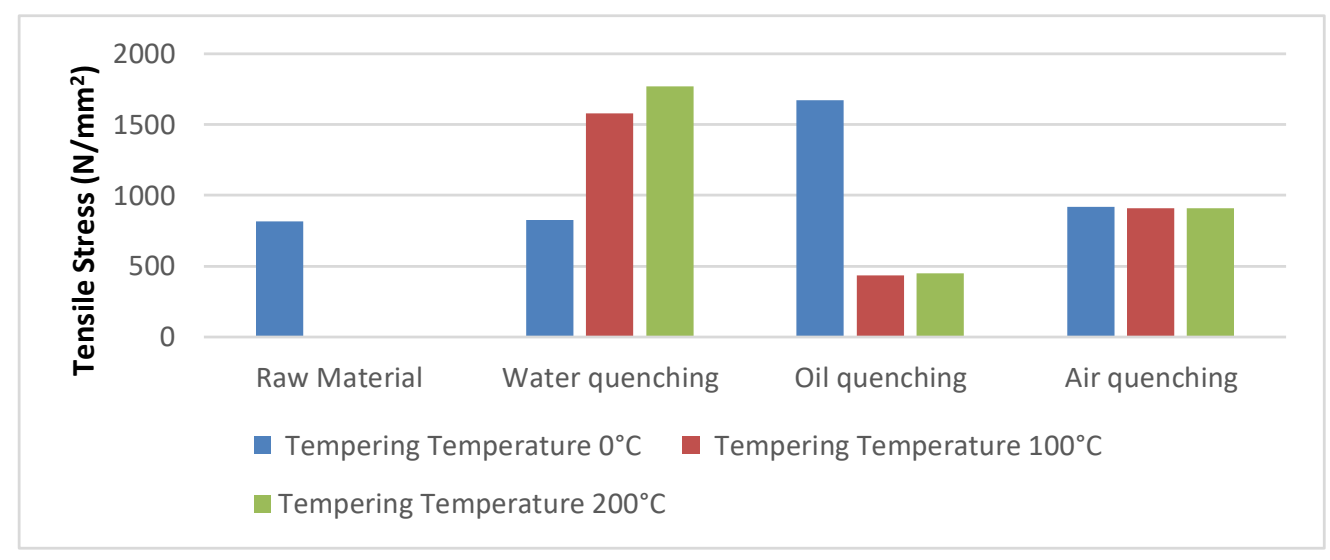

Fig. 13 Effect of Cooling Media on Tensile Voltage at Each Tempering Temperature

The data above also shows that tempering temperature has an influence on the tensile strength of the material, the tensile stress will first increase and then gradually decrease with increasing tempering temperature, as well as for the overvoltage (Liu et al, 2016). This is caused by the increase in tempering temperature of $\varepsilon$-carbide and cementite which will precipitate gradually from the initial one which is martensite. Tensile stress increases gradually because of the dispersion of reinforcing $\varepsilon$-carbides. On the other hand, an increase in tempering temperature further $\varepsilon$-carbide will change shape to cementite which will reduce the dispersion of reinforcement $\varepsilon$-carbide so that it can reduce the value of tensile stress.

In quenching data with air conditioning media, it shows that the tensile stress and its overvoltage increase first and then decrease with increasing tempering temperature. Data on the tensile stress possessed by the material with the quenching process of water does not appear to have decreased. This is because the tempering temperature has not reached its maximum point so that the data only show an increase without decrease. It actually decreases not linearly with the value of tensile stress rising, this is caused by a decrease in the quantity of residual austenite due to the tempering process. In quenching material with oil cooling media with no tempering process, there was an increase in both the yield stress value, tensile stress, and elongation, this was due to the presence of $\varepsilon$-carbide content in the material.

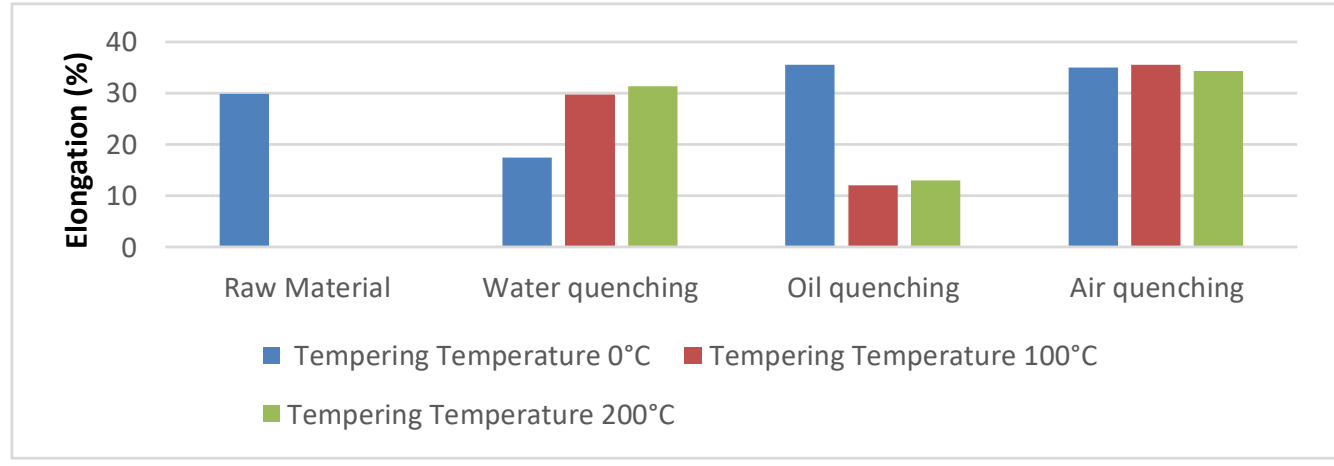

Fig. 14 The Influence of Cooling Media on Elongation on Tempering Temperatures

Elongation can also be affected by the tempering process, if the tempering temperature rises, the elongation will also increase (Canale and Totten, 2014). However, in data with an elongation oil cooling media, it decreases, a higher cooling rate allows the material to have a high carbide density in its ferrite phase, which can disrupt formability of the material so that the elongation decreases. 


\subsection{IMPACT TEST RESULTS}

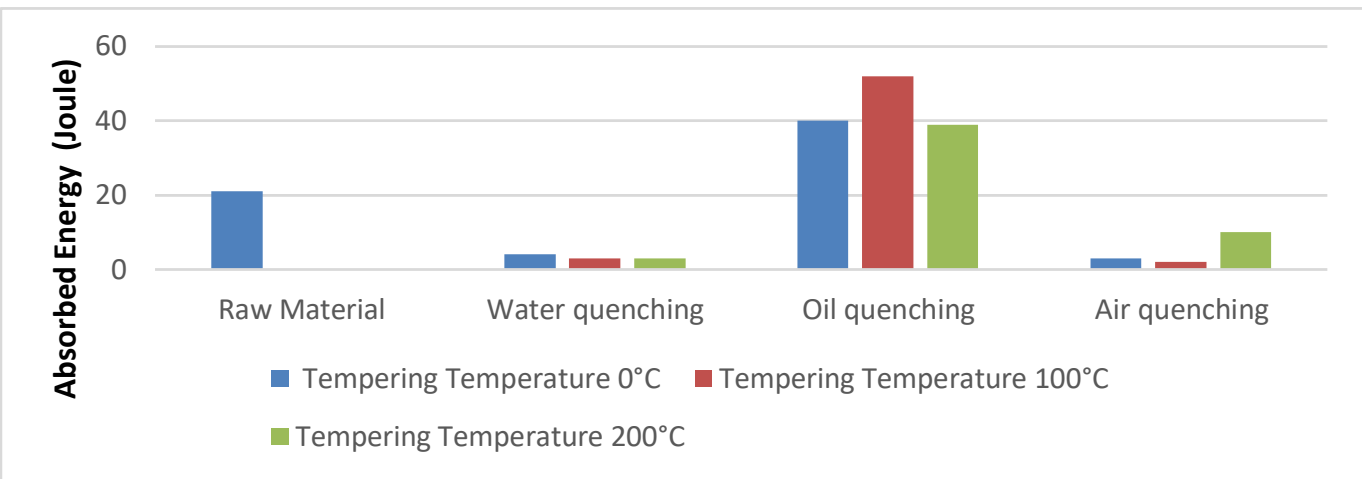

Fig. 15 Impact of Cooling Media on Impact Resistance on Tempering Temperature

The tempering process also affects the value of material impact resistance, along with the increase in tempering temperature, the impact resistance value will also increase (Mishra et al, 2009). The graph in Figure 4.11 about hardness, Figure 4.12, Figure 4.13, and Figure 4.14 about tensile strength and Figure 4.15 about impact resistance have a correlation where the martensite phase formed due to the heat treatment process comes with the distortion which will gradually increase ductility and material impact resistance.

It can be seen that in some data with even lower impact resistance values, this is because the tempering process which occurs under temperatures of $300^{\circ} \mathrm{C}$ cannot be completely removed.

Tempering temperatures that are too low cause a tempered martensite embrittlement event which is a result from the presence of cementite precipitation on the austenite prior grain boundary or deep grain boundary and the separation of impurity at the austenite grain boundary. Events where the value of impact resistance decreases is usually called tempered martensite embrittlement (TME). As with secondary hardening events in hardness, steel containing one or more carbide-forming elements $(\mathrm{Cr}, \mathrm{Mo}, \mathrm{V}$, and $\mathrm{W})$ is more likely to experience TME. Materials with high $\mathrm{P}$ or $\mathrm{C}$ content also allow you to experience TME.

\section{CONCLUSION}

Based on the results of research that have been done, it can be concluded that:

The quenching and tempering process influences the transformation of laterite microstructure, including:

1) Microstructure transformation from raw material which initially has ferrite and pearlite phases, after processing quenching turns into residual martensite and austenite.

2) The transformation of microstructure from the initial martensite and austenite residue from the quenching process, after being processed tempering into tempered martensite, $\varepsilon$-carbide, ferrite and pearlite.

The quenching and tempering process influences the improvement of mechanical properties, especially hardness, tensile strength, and impact resistance on laterite steel, including:

1) The highest hardness is obtained from the test specimens from the quenching process with water cooling media followed by the tempering process at a temperature of $100^{\circ} \mathrm{C}$.

2) The highest yield stress obtained in the test specimens from the quenching process with water cooling media followed by the tempering process at $100^{\circ} \mathrm{C}$, the highest tensile stress obtained on the test specimens from quenching process with water 
cooling media followed by tempering at $200^{\circ} \mathrm{C}$, and the highest elongation obtained in the specimen test results of the quenching process with oil cooling media and on the test specimens resulting from the quenching process with air cooling media followed by the tempering process at a temperature of $100^{\circ} \mathrm{C}$. The most stable tensile strength is obtained from specimens by quenching with air conditioning media with or without the tempering process.

3) The highest impact resistance is obtained from the test specimens resulting from the quenching process with oil cooling media followed by the tempering process at a temperature of $100^{\circ} \mathrm{C}$.

\section{ACKNOWLEDGMENTS}

This research is original research that has no conflict of interest.

\section{REFERENCES}

[1] Bandanadjaja, Beny. 2010. Modification and Development of Commercial Steel AISI 4340 As bulletproof Steel. Technology Development and Application Journal (PPT) 8(1): 1-6.

[2] Yanuar, P., Sri Nugroho, and Yurianto. 2014. Characterization of Steel Armour From Results of Quenching and Tempering Processes. Proseding SNST ke-5. Wahid Hasyim University. Semarang. 1318.

[3] Koesnohadi and A., Sobandi. 2008. Potential of Local Resources to Build Independence and Competitiveness of the National Steel Industry. Paper presented at the Colloquium Symposium Tekmira. Bandung. 5-6 November.

[4] Sufriadin, Sri Widodo, and Rapuan Bintang. 2013. Characterization of Mineralogy of Laterite Iron Ore and It's Potential as Raw Materials for Steel Industry in Indonesia. Prosiding 2013 Research Results of the Engineering Faculty. Hasanuddin University. Makassar. 1-4.

[5] Yusuf and Edi Herianto. 2008. The Making of Iron Nugget from Iron Sand and Laterite Iron Ore: Challenges and Possibilities for Success. Metallurgy Journal 23(2): 87-93.

[6] Purwanto, H., R. Soenoko, A. Purnowidodo, and A. Suprapto. 2015. Macro and Micro-Aluminum Plate Characteristics of Ballistic Endurance. Prosiding SNST ke-6. Wahid Hasyim University. Semarang. $97-$ 102.

[7] National Institute of Justice U.S. Department of Justice. 1985. Ballistic Resistant Protective Materials. Technology Assessment Program. Washington DC: National Criminal Justice Reference Service.

[8] Haryadi, G. D. 2006. The Effect of Tempering Temperature on Hardness, Tensile Strength, and Micro Structures on Steel K-460. Rotation Jurnal 8(2): 1-8.

[9] Barlow, L. D. and Du Toit M. 2012. Effect of The Austenitizing Heat Treatment on The Microstructure and Hardness of Martensitic Stainless Steel AISI 420. Journal of Materials Engineering and Performance 21(7): 1327-1336.

[10] He, A. and J. Zeng. 2016. Direct Preparation of Low Ni-Cr Alloy Cast Iron From Red Mud and Laterite Nickel Ore. Journal Materials and Design 115(2017): 433-440.

[11] Herbirowo, S., and B. Adjiantoro. 2016. The Effect of Heat Treatment on Micro Structures and Mechanical Strength of Laterite Nickel Steel. Widyariset Journal 2(2): 153-160.

[12] ASM International. 1991. ASM Handbook. Volume 4 Heat Treating. United States of America: ASM International Handbook Committee.

[13] Azhari, Ahmad. 2012. The Effect of Tempering Process and Scraping Process Below and Above Recrystallization Temperature on Medium Carbon Steel Against Hardness and Toughness and Micro Structures for Permanent Palm Blade Eyes. E-Dynamic Journal 2(2): 10-22.

[14] ASM International. 2004. ASM Handbook. Volume 4 Metallography and Microstructures. United States of America: ASM International Handbook Committee.

[15] Junior, W. D. C., and D. G. Rethwisch. 2016. Materials Science and Engineering An Introduction. $8^{\text {th }}$ ed. United States of America: John Wiley \& Sons Inc.

[16] Murtiono, Arief. 2012. Effect of Quenching and Tempering on Hardness and Tensile Strength and Micro Structures of Medium Carbon Steel for Palm Harvesters Blades. E-Dynamic Journal 2(2): 57-70.

[17] Jena, P. K., B. Mishra, M. RameshBabu, A. Babu, A. K. Singh, K. Sivakumar, and T. B. Bhat. 2009. Effect of Heat Treatment on Mechanical and Ballistic Properties of A High Strength Armour Steel. International Journal of Impact Engineering 37(2010): 242-249.

[18] Smallman, R.E., and R. J. Bishop. 1995. Modern Physical Metallurgy and Materials Engineering. $6^{\text {th }}$ Edition.Reed Educational and Professional Publishing Ltd. New Zealand. Terjemahan S. Djaprie. 2000. Modern Physical Metallurgy and Material Engineering.Jakarta: Erlangga.

[19] Dieter, George E. 1986. Mechanical Metallurgy. $3^{\text {rd }}$ ed. Singapore: McGraw-Hill Book Company.

[20] Sugiyono. 2012. Metode Penelitian Kuantitatif, Kualitatif, dan R\&D. Bandung: Alfabeta. 
[21] Surdia T., and Kenji Chijiwa. 2000. Metal Casting Technique. Second edition. Eighth print.Jakarta: Pradnya Paramita.

[22] Jena, P. K., K. S. Kumar, V. R. Krishna, A. K. Singh, and T. B. Bhat. 2007. Studies on The Role of Microstructure on Performance of A High Strength Armour Steel. Journal Engineering Failure Analysis 15 .2008: 1088-1096.

[23] Liu, F., X. Lin, M. Song, H. Yang, K. Song, P. Guo, and W. Huang. 2016. Effect of Tempering Temperature on Microstructure and Mechanical Properties of A Laser Solid Formed 300M Steel. Journal of Alloys and Compounds 689.2016: 225-232.

[24] Canale, L.C.F., J. Vatavuk, and G.E. Totten. 2014. Introduction to Steel Heat Treatment. Journal Comprehensive Materials Processing 12(2): 1-37. 